\title{
Tissue Engineering of a Bioartificial Kidney
}

\author{
Deborah A. Cieslinski and H. David Humes* \\ University of Michigan and Veteran's Administration Medical Center, \\ 2215 Fuller Road, Ann Arbor, Michigan 48105
}

Received June 25, 1993/Accepted November 1, 1993

Tissue engineering is a rapidly growing field in biotechnology. The use and packaging of synthetic materials, biologic compounds, and cellular components of specific tissues can be envisioned to replace physiologic function of diseased organs. Long-term ex vivo therapy for kidney failure has been achieved, so that the kidney may be the first solid organ in which tissue engineering concepts can produce an implantable device for long-term in vivo replacement therapy. To replace the kidney's excretory function, an implantable bioartificial kidney requires both a device to replace blood ultrafiltration performed by renal glomeruli and a device to replace transport regulatory function of the renal tubule. The initial concepts for these devices are just beginning to be considered and developed. (c) 1994 John Wiley \& Sons, Inc.

Key words: kidney - bioartificial kidney - blood ultrafiltration

\section{INTRODUCTION}

Tissue engineering is a rapidly developing field in biotechnology. Recent progress towards ex vivo keratinocyte growth for skin grafting, ex vivo growth of hematopoietic cells for blood production, and ex vivo growth of hepatocytes for liver replacement have been documented. $^{21,24,26}$ In this regard, support of renal function with hemodialysis or chronic ambulatory peritoneal dialysis (CAPD) has been the only successful long-term ex vivo replacement therapy to date. ${ }^{8,16}$ Accordingly, the kidney may well be the first solid organ in which tissue engineering concepts can produce an implantable device for in vivo replacement therapy, thereby replacing renal function in patients with end-stage renal disease (ESRD) to circumvent the need for long-term dialytic therapy.

Although long-term chronic renal replacement therapy with either hemodialysis or CAPD has dramatically changed the prognosis of renal failure, it is not complete replacement therapy, because it only provides filtration function (usually on an intermittent basis) and does not replace the homeostatic, regulatory, and endocrine functions of the kidney. Because of the nonphysiologic manner in which dialysis performs or does not perform the most critical renal functions, patients with ESRD on dialysis continue to have major medical, social, and economic problems. ${ }^{8}$

Accordingly, this new technology would most likely have substantial benefits for the patient by increasing life

\footnotetext{
* To whom all correspondence should be addressed.
}

expectancy, increasing mobility and flexibility, increasing quality of life with large savings in time, less risk of infection, and reduced costs. This approach could also be considered a cure rather than a treatment for patients.

\section{STEM OR PROGENITOR CELLS}

Critical to the advancement of the tissue engineering field is the need for the isolation and growth in vitro of specific cells from adult tissue. These cells are those that possess stem cell-like characteristics with a high capacity for selfrenewal and the ability to differentiate under defined conditions into specialized cells to develop correct structure and functional components of a physiologic organ system..$^{9,11,22}$ Stem cells have been extensively studied in only three adult mammalian tissues: the hematopoietic system, the epidermis, and the intestinal epithelium. Recent work has also suggested that stem cells may also reside in the adult nervous system. ${ }^{23}$ Little insight into possible renal tubule stem cells had been developed until recent data demonstrating methodology to isolate and grow renal proximal tubule stem or progenitor cells from adult mammalian kidneys. ${ }^{13,14}$ This series of studies was promoted by the clinical and experimental observations suggesting that renal proximal tubule progenitor cells must exist, because they have the ability to regenerate after severe nephrotoxic or ischemic injury to form a fully functional and differentiated epithelium. ${ }^{6,15}$ Whether proximal tubule progenitor cells are pluripotent, possessing the ability to differentiate into cells of other segments (such as loop of Henle, distal convoluted tubule) as in embryonic kidney development, is presently unclear; the clinical state of acute tubular necrosis certainly supports the idea that proximal tubule progenitor cells have the ability to replicate and differentiate into proximal tubule cells with functionally and morphologically differentiated phenotypes.

In this regard, recent data ${ }^{13}$ have demonstrated, using renal proximal tubule cells in primary culture, that the growth factors, TGF- $\beta 1$ and EGF, along with the retinoid, retinoic acid, promoted tubulogenesis in renal proximal tubule progenitor cells in tissue culture. These observations defined a coordinated interplay between growth factors and retinoids to induce pattern formation and morphogenesis. This finding is one of the first definitions of inductive factors which may be important in the organogenesis of 
a mammalian organ. In addition, using immunofluorescence microscopy, retinoic acid induced laminin $\mathrm{A}$ - and $\mathbf{B}_{1}$-chain production in these cells and purified soluble laminin completely substituted for retinoic acid in kidney tubulogenesis. These results clearly demonstrate the manner in which retinoic acid, as a morphogen, can promote pattern formation and differentiation by regulating the production of an extracellular matrix molecule.

Further work has demonstrated, in fact, that a population of cells resides in the adult mammalian kidney which have retained the capacity to proliferate and morphogenically differentiate into tubule structures in vitro. ${ }^{14}$ These experiments have identified non-serum-containing growth conditions, which select for proximal tubule cells with a high capacity for self-renewal and an ability to differentiate phenotypically, collectively, and individually, into proximal tubule structures in collagen gels. Regarding the high capacity for self renewal, genetic marking of the cells with a recombinant retrovirus containing the lac $\mathrm{Z}$ gene and dilution analysis demonstrated that in vitro tubulogenesis often arose from clonal expansion of a single genetically tagged progenitor cell. These results suggest that a population of proximal tubule cells exist within the adult kidney in a relatively dormant, slowly replicative state, but with a rapid potential to proliferate, differentiate, and pattern form to regenerate the lining proximal tubule epithelium of the kidney following severe ischemic or toxic injury. The methodology to purify and grow renal tubule progenitor cells allows for the possibility to provide better therapeutic alternatives to current expensive medical substitution therapies for the treatment of end-stage renal failure by replacing filtering, regulatory, and endocrine properties of kidney tissue.

\section{TISSUE ENGINEERING FORMULATION}

In designing an implantable bioartificial kidney for renal replacement function, essential functions of kidney tissue must be appreciated to direct the design of the tissue engineering project. The kidneys are solid organs critical to body homeostasis due to their excretory, regulatory, and endocrinologic functions. The excretory function is initiated by filtration of blood at the glomerulus, which is an enlargement of the proximal end of the tubule incorporating a vascular tuft. The structure of the glomerulus is designed to provide efficient ultrafiltration of blood to remove toxic wastes from the circulation and retain important components within the systemic circulation, such as albumin. 2,3 The regulatory function of the kidney, especially with regard to fluid and electrolyte homeostasis, is provided by the tubular segments attached to the glomerulus. The ultrafiltrate emanating from the glomerulus courses along the kidney tubule, which reabsorbs fluid and solutes to finely regulate the excretion of various amounts of solutes and water in the final urine. The functional unit of the kidney is, therefore, composed of the filtering unit, the glomerulus, and the regulatory unit, the tubule. Together they form the basic component of the kidney, called the nephron. Therefore, a bioartificial kidney requires two main units, glomeruli and renal tubules.

\section{Bioartificial Glomerulus}

The potential for a bioartificial glomerulus has been achieved with the use of polysulphone fibers ex vivo with maintenance of ultrafiltration in humans for several weeks with a single device. ${ }^{10,19}$ The availability of hollow fibers with high hydraulic permeability has been an important advancement in biomaterials for replacement function of glomerular ultrafiltration. Conventional hemodialyses for ESRD have used membranes in which solute removal is driven by a concentration gradient of the solute across the membranes and is, therefore, predominantly a diffusive process. Another type of solute transfer also occurs across the dialysis membrane via a process of ultrafiltration of water and solutes across the membrane. This convective transport is independent of the concentration gradient and depends predominantly on the hydraulic pressure gradient across the membrane. Both diffusive and convective processes occur during traditional hemodialysis, but diffusion is the main route of solute movement.

The development of synthetic membranes with high hydraulic permeability and solute retention properties in convenient hollow fiber form has promoted ESRD therapy based upon convective hemofiltration rather than diffusive hemodialysis., ${ }^{72}$ Removal of uremic toxins, predominantly by the convective process, has several distinct advantages, because it imitates the glomerular process of toxin removal with increased clearance of higher-molecular-weight solutes and removal of all solutes (up to a molecular weight cutoff) of the same rate. The comparison of the differences between diffusive and convective transport across a semipermeable membrane is detailed in Figure 1. This figure demonstrates the relationship between molecular size and clearance by diffusion and convection. As seen, the clearance of a molecule by diffusion is negatively correlated with the size of the molecule. In contrast, clearance of a substance by convection is independent of size up to a certain molecular weight cutoff. The bulk movement of water carries passable solutes along with it in approximately the same concentration as in the fluid.

Development of an implantable device which mimics glomerular filtration will thus be dependent upon convective transport. This physiologic function has been achieved clinically with the use of polysulphone hollow fibers ex vivo. Major limitations to the currently available technology for long-term replacement of filtration function include bleeding associated with required anticoagulation, diminution of filtration rate due to protein deposition in the membrane over time, and large amounts of fluid replacement required to replace the ultrafiltrate formed from the filtering unit. The use of endothelial cell seeded conduits and filtration surfaces may provide improved longterm hemocompatibility and hemofiltration in vivo. ${ }^{18,25,27}$ 


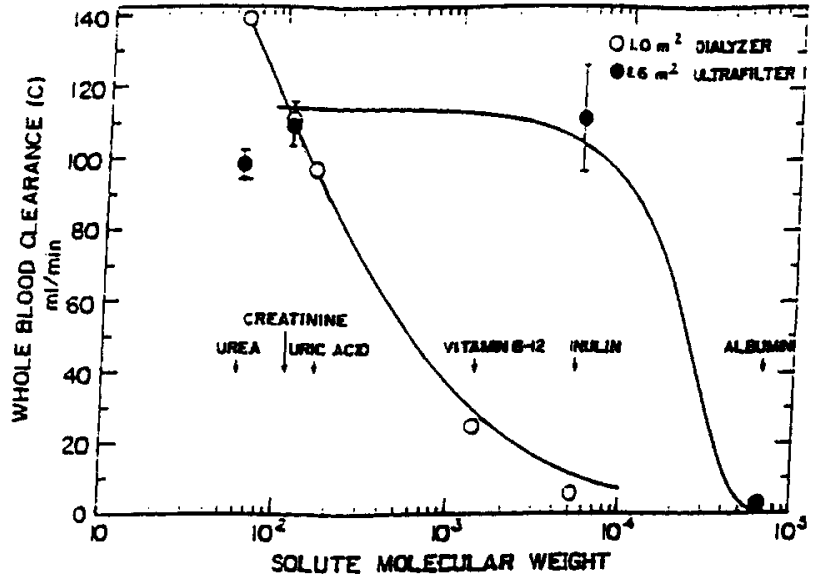

Figure 1. Relationship between solute molecular size and clearance by diffusion (open circles) and convection (closed circles). Left curve shows solute clearance for a $1.0 \mathrm{~m}^{2}$ dialyzer with no ultrafiltration where solute clearance is by diffusion. Right curve shows clearance for a $1.6 \mathrm{~m}^{2}$ ultrafilter where solute clearance is by convection. Smaller molecules are better cleared by diffusion; larger molecules by convection. Normal kidneys clear solutes in a pattern similar to convective transport. (Figure adapted from Reference 17.)

In this regard, endothelial cell seeding of small caliber vascular prosthesis has been shown experimentally to reduce long-term platelet deposition, thrombus formation, and loss of graft patency. ${ }^{27}$ Recent results in humans have demonstrated success in autologous endothelial cell seeding in small caliber grafts after growth of these cells along the graft lumen ex vivo to achieve a confluent monolayer prior to implantation. Long-term persistent endothelialization and patency of the implanted graft has been reported. ${ }^{18}$

For differentiated endothelial cell morphology and function, an important role for various components of the extracellular matrix (ECM) has been demonstrated. ${ }^{4,5}$ The ECM has been clearly shown to dictate phenotype and gene expression of endothelial cells, thereby modulating morphogenesis and growth. Various components of ECM, including collagen type I, collagen type IV, laminin, and fibronectin have been shown to affect endothelial cell adherence, growth, and differentiation. Of importance, ECM produced by MDCK cells, a permanent renal epithelial cell line, has the ability to induce capillary endothelial cells to produce fenestrations. ${ }^{5,20}$ Endothelial cell fenestrations are large openings, which act as channels for convective transport through the endothelial monolayer, and are important in the high hydraulic permeability characteristic of glomerular capillaries. Thus, the ECM component on which the endothelial cells attach and grow may be critical in the functional characteristics of the lining monolayer.

\section{Bioartificial Tubule}

The bioartificial renal tubule is also clearly feasible when conceived as a combination of living cells supported on polymeric substrata. ${ }^{17} \mathrm{~A}$ bioartificial tubule uses epithelial progenitor cells cultured on water and solute-permeable membranes seeded with various biomatrix materials, so that expression of differentiated vectorial transport and metabolic and endocrine function is attained. With appropriate membranes and biomatrices, immunoprotection of cultured progenitor cells can be achieved concurrent with long-term functional performance as long as conditions support tubule cell viability. ${ }^{1,17}$ The technical feasibility of an implantable epithelial cell system derived from cells grown as confluent monolayers along the luminal surface of polymeric hollow fibers has been achieved. ${ }^{17}$ These previously constructed devices, however, have used permanent renal cell lines which do not have differentiated transport function. The ability to purify and grow renal proximal tubule progenitor cells with the ability to differentiate morphogenically may provide a capability for replacement renal tubule function.

A bioartificial proximal tubule satisfies a major requirement of reabsorbing a large volume of filtrate to maintain salt and water balance within the body. The need for additional tubule equivalents to replace another nephronal segment function, such as the loop of Henle, to perform more refined homeostatic elements of the kidney, including urine concentration or dilution, may not be necessary. Patients with moderate renal insufficiency lose the ability to finely regulate salt and water homeostasis--because they are unable to concentrate or dilute, yet are able to maintain reasonable fluid and electrolyte homeostasis due to redundant physiologic compensation via other mechanisms. Thus, a bioartificial proximal tubule, which reabsorbs isoosmotically the majority of the filtrate, may be sufficient to replace required tubular function to sustain fluid electrolyte balance in a patient with end-stage renal disease.

\section{Implantable Bioartificial Kidney}

The development of a bioartificial filtration device and a bioartificial tubule processing unit would lead to the possibility of an implantable bioartificial kidney, consisting of the filtration device followed in series by the tubule unit. The filtrate formed by this device will flow directly into the tubule unit. The tubule unit should maintain viability, because metabolic substrates and low-molecular-weight growth factors are delivered to the tubule cells from the ultrafiltration unit. Furthermore, immunoprotection of the cells grown within the hollow fiber is achievable due to the impenetrance of immunologically competent cells through the hollow fiber. Rejection of transplanted cells will, therefore, not occur. This arrangement thereby allows the filtrate to enter the internal compartments of the hollow fiber network, which are lined with confluent monolayers of renal tubule cells for regulated transport function.

This device could be used either extracorporeally or implanted within a patient. In this regard, the specific implant site for a bioartificial kidney will depend upon the final configuration of both the bioartificial filtration 
and tubule device. As presently conceived, the endotheliallined bioartificial filtration hollow fibers can be placed into an arteriovenous circuit using the common iliac artery and vein, similar to the surgical connection for a renal transplant. The filtrate is connected in series to a bioartificial proximal tubule, which is embedded into the peritoneal membrane, so that reabsorbate will be transported into the peritoneal cavity and reabsorbed into the systemic circulation. The processed filtrate exiting the tubule unit is then connected via tubing into the proximate ureter for drainage and urine excretion via the recipient's own urinary collecting system.

The clinical implications of this final product development are substantial. Although long-term chronic renal replacement therapy with either hemodialysis or CAPD has dramatically changed the prognosis of renal failure, it is not complete replacement therapy, because it only provides filtration function (usually on an intermittent basis) and does not replace the homeostatic, regulatory, and endocrine functions of the kidney. Because of the nonphysiologic manner in which dialysis performs or does not perform the most critical renal functions, patients with ESRD on dialysis continue to experience major medical, social, and economic problems. These include a life expectancy rate one fifth that of a normal cohort group, a five-times-higher hospitalization rate than normal, a $60 \%$ unemployment rate, and a $30 \%$ disability rate. Accordingly, this new technology, based upon these bioengineering products, will most likely have substantial benefits to the patient by increasing life expectancy; increasing mobility and flexibility; and increasing quality of life with large savings in time, less risk of infection, and reduced costs. This approach could also be considered a cure rather than a treatment for patients.

\section{References}

1. Aebischer, P., Wahlberg, L., Tresco, P. A., Winn, S. R. 1991. Macroencapsulation of dopamine-secreting cells by coextrusion with an organic polymer solution. Biomaterials 12: $50-56$.

2. Brenner, B. M., Humes, H. D. 1977. Mechanisms of glomerular ultrafiltration. N. Engl. J. Med. 297: 148-154.

3. Brenner, B. M., Hostetter, T. H., Humes, H. D. 1978. Molecular basis of proteinuria of glomerular origin. N. Engl. J. Med. 298: 826-833.

4. Carey, D. J. 1991. Control of growth and differentiation of vascular cells by extracellular matrix proteins. Ann. Rev. Physiol. 53: $161-177$.

5. Carley, W.W., Milici, A. J., Madri, J.A. 1988. Extracellular matrix specificity for the differentiation of capillary endothelial cells. Exp. Cell Res. 178: $426-434$.

6. Coimbra, T., Cieslinski, D. A., Humes, H. D. 1990. Exogenous epidermal growth factor enhances renal repair in mercuric chloride-induced acute renal failure. Am. J. Physiol. 259: F483-F443.

7. Colton, C. K., Henderson, L.W., Ford, C. A., Lysaght, M. J. 1975. Kinetics of hemodiafiltration. I. In vitro transport characteristics of a hollow-fiber blood ultrafilter. J. Lab. Clin. Med. 85: 355-371.
8. Excerpts from United States Renal Data System. 1991. Annual Data Report (November 1991). Prevalence and cost of ESRD therapy. Am. J. Kidney Dis. 18(suppl. 2): 21-30.

9. Garlick, J. A., Katz, A. B., Fenjves, E. S., Taichman, L. B. 1991. Retrovirus-mediated transduction of cultured epidermal keratinocytes. J. Invest. Dermatol. 97: 824-829.

10. Golper, T.A. 1986. Continuous arteriorvenous hemofiltration in acute renal failure. Am. J. Kidney Dis. 6: 373-381.

11. Hall, P. A., Watt, F. M. 1989. Stem cells: the generation and maintenance of cellular diversity. Development 106: 619-633.

12. Henderson, L. W., Colton, C. K., Ford, C. A. 1975. Kinetics of hemodiafiltration. II. Clinical characterization of a new blood cleansing modality. J. Lab. Clin. Med. 85: 372-391.

13. Humes, H. D., Cieslinski, D.A. 1992. Interaction between growth factors and retinoic acid in the induction of kidney tubulogenesis. Exp. Cell Res. 201: 8-15.

14. Humes, H.D., Krauss, J.C., Cieslinski, D. A., Funke, A. J. Tubulogenesis from isolated single cells of adult mammalian kidney: clonal analysis with a recombinant retrovirus (submitted).

15. Humes, H.D., Cieslinski, D. A., Coimbra, T., Messana, J. M., Galvao, C. 1989. Epidermal growth factor enhances renal tubule cell regeneration and repair and accelerates the recovery of renal function in postischemic acute renal failure. J. Clin. Invest. 84: 1757-1761.

16. Iglehart, J. K. 1993. The American health care system; the End Stage Renal Disease Program. N. Engl. J. Med. 328: 366-371.

17. Ip, T.K., Aebischer, P. 1989. Renal epithelial-cell-controlled solute transport across permeable membranes as the foundation for a bioartificial kidney. Artif. Organs 13: 58-65.

18. Kadletz, M., Magometschnigg, H., Minar, E., Konig, G., Grabenwoger, M., Grimm, M., Wolner, E. 1992. Implantation of in vitro endothelialized polytetrafluoroethylene grafts in human beings. J. Thorac. Cardiovasc. Surg. 104: 736-742.

19. Kramer, P., Wigger, W., Rieger, J., Matthaei, D., Scheler, F. 1977. Arterior-venous haemofiltration: a new and simple method for treatment of overhydrated patients resistant to diuretics. Klin. Wochenschr 55: $1121-1122$.

20. Milici, A. J., Furie, M. B., Carley, W.W. 1985. The formation of fenestrations and channels by capillary endothelium in vitro. Proc. Nati. Acad. Sci. 82: 6181-6185.

21. Parenteau, N. L., Nolte, C.M., Bilbo, P., Rosenberg, M., Wilkins, L. M., Johnson, E. W., Watson, S., Mason, V.S., Bell, E. 1991. Epidermis generated in vitro: practical considerations and applications. J. Cell Biochem. 45: 245-251.

22. Potten, C. S., Loeffier, M. 1990. Stem cells; lessons for and from the crypt. Development 110: 1001-1020.

23. Reynolds, B. A., Weiss, S. 1992. Generation of neurons and astrocytes from isolated cells of the adult mammalian central nervous system. Science 255: 1707-1710.

24. Rozga, J., Williams, F., Ro, M., Neuzil, D.F., Giorgio, T.D., Backfisch, F., Moscioni, A.D., Hakim, R., Demetriou, A. A. 1993. Development of a bioartificial liver: properties and function of a hollow-fiber module inoculated with liver cells. Hepatology 17: 258-265.

25. Schnider, P.A., Hanson, S. R., Price, T.M., Harker, L.A. 1988. Durability of confluent endothelial cell monolayers of small-caliber vascular prostheses in vitro. Surgery 103: 456-462.

26. Schwartz, R.M., Emerson, S. G., Clarke, M.F., Palsson, B. O. 1991. In vitro myelopoiesis stimulated by rapid medium exchange and supplementation with hematopoietic growth factors. Blood $\mathbf{7 8}$ 3155-3161.

27. Shepard, A.D., Eldrup-Jorgensen, J., Keough, E. M., Foxall, T.F., Ramberg, K., Connolly, R.J., Mackey, W.C., Gavris, B., Auger, K. R., Libby, P., O'Donnell, T.F., Callow, A. D. 1986. Endothelial cell seeding of small-caliber synthetic grafts in the baboon. Surgery 99: $318-325$. 